\title{
La enfermedad y sus causas en el siglo XIX chileno: La mirada del doctor Guillermo Blest
}

\author{
Disease and its causes in 19th century Chile: Dr. Guillermo Blest's view
}

Paula Caffarena B. ${ }^{1}$

${ }^{1}$ Escuela de Historia, Universidad Finis Terrae.

Este artículo forma parte del proyecto financiado por ANID/CONICYT, programa Fondecyt de Iniciacion Nº 11170571.

Recibido: 2 de Agosto de 2020

\section{Resumen}

Este artículo analiza el pensamiento médico del doctor Guillermo Blest, expuesto tanto en los informes médicos que envió a las autoridades de gobierno como en un escrito que publicó en 1828 titulado "Ensayo sobre las causas más comunes y activas de las enfermedades que se padecen en Santiago de Chile con indicaciones de los mejores medios para evitar su destructora influencia". En ellos, Blest presenta los principios de irritabilidad (Broussais) y excitabilidad (Brown) como elementos centrales para explicar las causas de las enfermedades. Asimismo, se observa la pervivencia de la teoría miasmática que coexiste con dichos principios explicativos, lo que le permite a Blest configurar un cuadro explicativo de la enfermedad.

Palabras clave: pensamiento médico; enfermedad; Blest; excitabilidad; irritabilidad; miasmas.

$\mathrm{E}$ studiar las enfermedades que a lo largo de la historia han afectado a la población, nos conduce a mirar un conjunto de situaciones que van más allá de los aspectos biológicos. Como bien ha señalado el historiador Diego Armus, "las enfermedades son fenómenos complejos, algo más que un virus o una bacteria (...) cargan con un repertorio de prácticas y construcciones discursivas que reflejan la historia intelectual e institucional de la medicina"1.

La presencia de la enfermedad durante los primeros cincuenta años del siglo XIX fue recurrente y ello propició que los médicos reflexionaran en torno a sus causas, construyendo discursos teóricos que permitieron comprender, en el marco de los conocimientos médicos de la época, las causas generales y particulares de las enfermedades que aquejaban a Chile.

\section{Correspondencia a:}

Paula Caffarena Barcenilla

pcaffarena@uft.cl

\begin{abstract}
This article aims to analyze the medical thought of Doctor Guillermo Blest, exposed both in the medical reports that he sent to the government authorities and in a document that he published in 1828 entitled "Assay on the most common and active causes of the diseases that are suffered in Santiago de Chile with indications of the best means to avoid its destructive influence". In them, Blest presents the principles of irritability (Broussais) and excitability (Brown) as central elements to explain the causes of diseases. Likewise, the miasmatic theory coexists with these explanatory principles, allowing Blest to configure an explanatory panorama of the disease.
\end{abstract}

Keywords: medical thinking; Blest; disease; excitability; irritability; miasms.

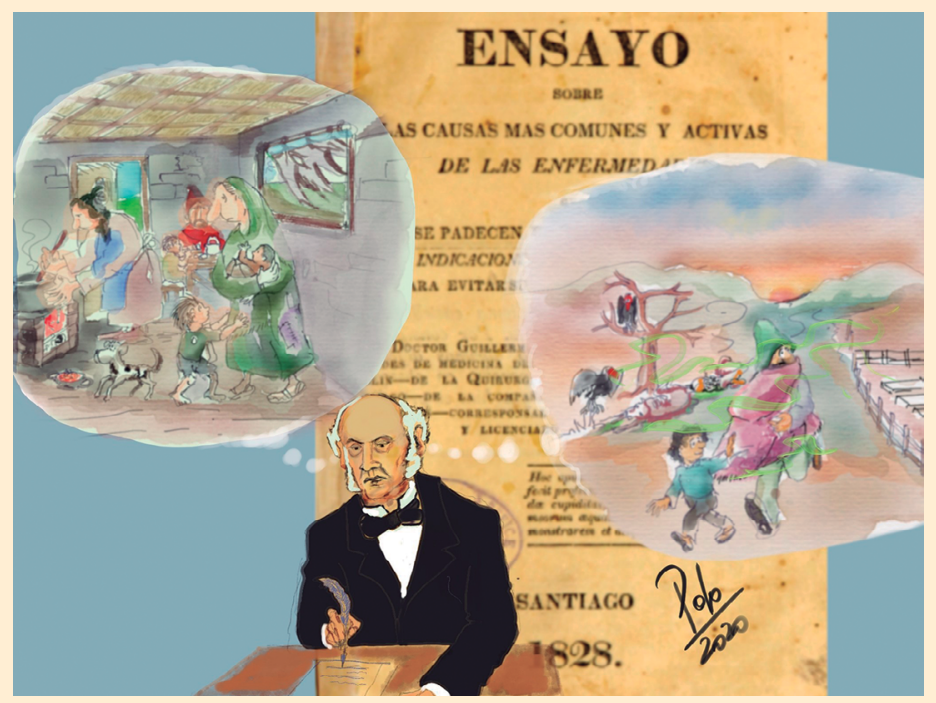


El objetivo central de este estudio es analizar aquella construcción discursiva, a partir de los escritos e informes médicos del doctor Guillermo Blest. Nos interesa estudiar las doctrinas interpretativas de la enfermedad que están tras los postulados de Blest, las causas que atribuyó a las enfermedades y sus formas de propagación, pues resultan ser elementos centrales en la comprensión de las condiciones sanitarias del período.

Nuestra hipótesis es que las explicaciones de Guillermo Blest respecto a las causas de las enfermedades, estuvieron influenciadas por diversas teorías médicas que circulaban a inicios del siglo XIX. Por una parte, se observa la influencia del fisiologismo, desarrollado tanto por John Brown como por François Broussier. Por otra, la persistencia de la teoría miasmática para explicar el origen de enfermedades epidémicas. La mixtura de dichas explicaciones, le permitió configurar un cuadro explicativo que integraba tanto los elementos de las teorías generales como las particularidades que observaba en el territorio chileno.

Testimonios como el que presenta Blest no son fáciles de encontrar, pues conforma una síntesis y balance de las condiciones sanitarias, del estado de la profesión médica y de los planteamientos teóricos vigentes sobre la enfermedad. Tanto en los informes que emitió a las autoridades de gobierno como en los impresos que de su autoría que circularon, demostró un interés por observar las causas de las enfermedades y no solo sus síntomas, lo cual lo llevó a fundamentar sus planteamientos en las teorías médicas que a inicios del siglo XIX circulaban en Europa.

\section{Guillermo Blest en Chile. Medicina y sociedad}

Guillermo Blest fue médico durante el Chile decimonónico. De origen irlandés, realizó sus estudios médicos en la Universidad de Edimburgo y Dublín. Llegó a Chile en 1824 y desde ese momento fue parte de la institucionalidad médica que existía en el país. En 1826 formó parte de la recién fundada Sociedad Médica y, en 1830 fue nombrado Presidente del Protomedicato ${ }^{2}$. Su activa voz en los temas sanitarios, quedó plasmada en sus informes y escritos. En 1826 publicó las "Observaciones sobre el actual estado de la medicina en Chile con la propuesta de un plan para su mejoría”, donde mostró su preocupación por la enseñanza de la medicina en Chile y los factores que la impedían y, dos años después, escribió el "Ensayo sobre las causas más comunes y activas de las enfermedades que se padecen en Santiago de Chile con indicaciones de los mejores medios para evitar su destructora influencia", mediante el cual expuso una serie de observaciones en torno al origen de las enfermedades. De acuerdo a lo señalado por Diego Barros Arana, esta publicación tuvo el mérito de ser "la primera producción de carácter científico que se hubiera dado a conocer en Chile sobre ese ramo de los conocimientos humanos" y obtuvo recursos del gobierno para la impresión de 50 ejemplares, los cuales se distribuyeron en el Congreso Nacional $^{3}$.

La trayectoria médica de Blest fue destacada. En 1826 integró la recién fundada Sociedad Médica que venía a reemplazar al Tribunal del Protomedicato de origen colonial. Sin embargo, las vicisitudes políticas de la época fueron moviendo a Blest de una institución a otra. Al asumir la Presidencia de la República, Ramón Freire el 4 de abril de 1827 suprimió la Sociedad Médica y creó la Inspección General de Medicina. Blest fue nombrado Inspector General y además Brigadier de Ejército para comandar la medicina militar chilena. Del mismo modo, cuando en 1831 el Presidente Francisco Antonio Pinto reestableció la Sociedad Médica, Blest continuó como su Presidente. En 1830 un nuevo cambio ocurría en la institucionalidad médica del país con el reestablecimiento del Protomedicato y Blest fue nombrado Presidente. Allí se mantuvo hasta 1836 , año en que se le acusó de no haber cumplido el deber de inspeccionar adecuadamente las boticas por un período de cinco años. Diego Portales, en ese momento Ministro de Interior, notificó a Blest que a causa de ello, "el Gobierno espera, por lo tanto, que el Dr. Blest observando en lo sucesivo una conducta más circunspecta, no dará lugar a nuevas quejas que escandalizan al Público y distraen al Gobierno de sus preferentes observaciones" . Sin embargo, Blest no se mantuvo en el cargo y decidió renunciar.

A lo largo de su ejercicio como médico, Blest observó con detención las condiciones sanitarias y las enfermedades que afectaban a los habitantes de Santiago. A través de los diferentes reportes que elaboró, mostró que la población estuvo fuertemente marcada por la presencia y la recurrencia de la enfermedad. Para Blest, "escasamente pasará uno sin que se presenten a nuestra vista los tristes efectos de alguna desastrosa enfermedad. Cada casa parece un hospital, y cada hospital un lúgubre teatro de las más espantosas dolencias con que el hombre puede ser atormentado" ${ }^{\circ}$. El médico hacía referencia a enfermedades como la viruela, disentería, tifus, escarlatina, fiebre puerperal entre otras, pues fueron dolencias recurrentes en los habitantes del período. Entre ellas, la viruela tuvo particular importancia, con aproximadamente veinte brotes epidémicos y una letalidad elevada, no dejó indiferente a la población. También la fiebre puerperal dejo una huella importante en la sociedad decimonónica, pues afectó fuertemente a las mujeres, con diversos brotes epidémicos durante el siglo XIX.

Esta situación motivó la búsqueda de respuestas en torno a qué condiciones presentaba Chile que la enfermedad parecía no dar tregua. Para Blest existían tres razones fundamentales que explicaban las causas de las 
que ocurrirían en Chile. Destacó la importancia de la influencia nerviosa en la producción de la enfermedad y consideró los principios de excitabilidad e irritabilidad como elementos explicativos claves en la condición de salud individual, pero también a nivel colectivo. Para Blest, por ejemplo, la irritabilidad era un principio central que existía en cada parte del ser humano y de él "dependen las saludables funciones de todos los órganos del cuerpo. Todo estímulo tiene el poder de elevar la acción de este principio y la acción así producida es proporcional a la fuerza del estímulo aplicado"9.

El calor del sol cumplía aquí un papel importante por su capacidad de aumentar la irritabilidad de los órganos. Blest indicaba que cuando la influencia del sol se producía en un grado equilibrado, éste permitía un suave estímulo que favorecía el funcionamiento del cuerpo, sin embargo, cuando dicho estímulo se elevaba, era uno de los más poderosos y penetrantes a que puede el hombre estar sujeto, destruyendo la natural irritabilidad de todos sus órganos, y por tanto induce esa debilidad de las fibras musculares, esa circulación lánguida, y esa falta de energía nerviosa que caracteriza tan particularmente la constitución de los naturales de Santiago ${ }^{10}$.

En términos específicos, Blest observó que el órgano cuya irritabilidad parecía excitarse de manera más común en los pacientes que veía en Santiago, era el hígado. Esta observación se respaldaba en que de veinte enfermos que atendía, dieciséis de ellos mostraban algún problema de carácter hepático. Su interpretación lo condujo a proponer que el calor del sol elevaba la irritabilidad de los vasos que se encontraban en el hígado y "esta irritabilidad así elevada, aumenta la acción de los vasos y sigue el acrecentamiento de la secreción biliaria, la congestión de los vasos hepáticos o una activa inflamación en el mismo hígado"11, siendo la causa de las más variadas enfermedades.

Del mismo modo, identificó cómo la temperatura atmosférica que actuaba como estímulo externo y sus variaciones, eran la causa de más de una enfermedad. La tisis, por ejemplo, podía ser causada por algún desorden en la secreción cuticular, el cual era ocasionado por la ausencia de transpiración. La influencia de la temperatura en el cutis resultó tener gran relevancia, ya que la piel fue vista como un órgano que permitía eliminar las secreciones del cuerpo humano. Las explicaciones de Blest destacaban que "el calor excitaba en los vasos del cutis una corriente de traspiración sobre toda la superficie del cuerpo". El frío, al contrario, reprimía la transpiración pues "constriñe la acción del cutis y disminuye su secreción, provocando que una gran cantidad de fluidos caiga en los vasos de los órganos internos ${ }^{12}$.

Ahora bien, el equilibrio entre los estímulos que el cuerpo recibía era el mejor garante de salubridad, pues solo de esa forma era posible mantener la armoniosa acción de todas las funciones del sistema. De este modo, 
enfermedades como la apoplejía podían encontrar su causa en la interrupción brusca del proceso de transpiración, pues se producía una hinchazón en los órganos internos, y el nuevo estímulo que de repente se ha producido no dejará de excitar enfermedad en uno u otro órgano en acción.

Recordamos haber visto en esta ciudad ahora dos años, un ejemplo de esta última violenta afección de apoplejía, que atacó a la persona de un acreditado abogado, que se expuso delante de una ventana abierta estando en traspiración, y desde ese momento hasta hoy ha quedado este apreciable individuo triste víctima de una parálisis ${ }^{13}$.

En esta misma línea interpretativa, Blest hizo una crítica contundente respecto a los alimentos que se consumían en Chile. Planteó que el consumo de alimentos con propiedades estimulantes y digestivas, como el aceite, la grasa, la mantequilla o aquellos fuertemente sazonados, era la causa más común de las enfermedades que afectaban a los órganos urinarios. Asimismo, la combinación de carne, ají, pimienta, ajo, cebolla, tomates, grasa, queso y dulces, resultaba en extremo perjudicial para la salud del individuo, pues excitaba en un grado tan grande al estómago "que hace comer a una persona más de lo que su estómago puede naturalmente contener". El problema que Blest expuso aquí fue el de la excitación permanente de una parte del cuerpo, en este caso, del estómago. De acuerdo al análisis que él realizaba, cuando ello ocurría "la irritabilidad de esa parte se agota y se suspenden sus funciones"14. Las consecuencias eran variadas, pues no solo se destruía la función digestiva, sino también otros órganos, como el corazón, podían verse afectados, pues la "acción estimulante sobre el estómago, excita una acción desordenada en la simpatía nerviosa que existe entre el corazón y este órgano"15.

Los diversos casos que Guillermo Blest expuso, dan cuenta de la aplicación de los principios de irritabilidad y excitabilidad para explicar el estado de salud de una persona. La influencia del medio externo actuaba de manera permanente, ya fuese a causa de las variaciones de temperatura o a través de los tipos de alimentos que ingería el individuo. Este marco explicativo permitió al médico irlandés dar respuesta a enfermedades de diferente índole, gastrointestinales, hepáticas, cerebrales e incluso la tisis. Sin embargo, estas explicaciones coexistieron con la difundida teoría miasmática que, con sus propios sustentos teóricos, permitió explicar el carácter epidémico que adquirían algunas enfermedades y, también, la relación entre las condiciones materiales en que vivía la población y la propagación de las enfermedades.

\section{Entre miasmas y epidemias: aire, higiene y pobreza}

Lo primero que Blest destacó fue la mala infraestructura urbana que tenía la ciudad de Santiago. Lo que en ese entonces se conocía como policía urbana, era para Blest "la principal y constante fuente de donde nace la mayor parte de las enfermedades". En ello, Blest incluía lo muy mal empedradas que se encontraban las calles y las acequias que, si bien en un inicio estuvieron destinadas a refrescar y limpiar la ciudad, ahora eran "receptáculos de toda clase de inmundicias, y no teniendo salida cómoda, mueren al derredor de la población en infeccionados charcos, eternos laboratorios de putrefacción". A ello se sumaban los suburbios donde vive la clase más pobre y numerosa que, "se hallan tan cargados de basura y lodo que es difícil transitarlos a caballo"16.

En el caso de las habitaciones de los más desposeídos, Blest llamaba la atención frente a las precarias condiciones de vivienda, donde el hacinamiento y la consiguiente falta de ventilación se transformaron en elementos claves para explicar las continuas enfermedades que afectaban a quienes vivían en la pobreza. Blest retrató crudamente dichas condiciones de vida, señalando que en casi todas las calles hay estrechos cuartos habitados por los artesanos y sus familias, donde no es raro encontrar siete $\mathrm{u}$ ocho personas amontonadas con perros y gatos, que satisfacen allí mismo todas sus naturales necesidades y sin otro conducto para alumbrar y ventilar este hato que las solas puertas ${ }^{17}$.

Blest daba cuenta de los nocivos efectos que ejercía en la salud la mala ventilación, pues el aire corrompido perjudicaba de dos formas a las personas. En primera instancia porque su reiterada aspiración impedía que la sangre experimentara la propia y necesaria mudanza de venosa en arterial, luego, porque debilitaba el sistema nervioso, lo que equivalía a indicar que "la venenosa influencia de tal aire en esos infelices, envilece las potencias de su alma, afloja sus espíritus y debilita la vis vitae de su naturaleza, hasta llegarlos a hacer fácil presa de las enfermedades y de la muerte". La contraparte de esta situación se vivía en el campo, pues allí se respira "libremente el aire atmosférico: ni aguas detenidas perturban con sus nocivos y pestíferos vapores el tranquilo y puro curso de su sangre. Tales son las delicias del campo, tales las causas que proporcionan salud y larga vida a sus habitantes"18.

Estas observaciones le permitieron a Blest constatar que la pobreza era un factor determinante en la recurrencia de la enfermedad, pues el hacinamiento y la falta de viviendas adecuadas influían en la propagación de la enfermedad. Por el contrario, quienes vivían en viviendas bien construidas, con buena ventilación y sin hacinamiento, enfermaban menos. Lo mismo ocurría en el campo, donde sus habitantes no padecían la miseria urbana y gozaban de mejor salud. En ambos casos la ventilación y la circulación del aire cumplieron un papel central y, en concordancia con los planteamientos de Brown y Brossais que consideraban que el "oxígeno era el más potente de los estímulos externos”, ello se debía a la 
expuestos a todos los rigores de la estación, exhalan los más pestilentes miasmas"23.

Las implicancias que esta teoría comenzó a tener son importantes de destacar, pues a través de ella, se explicó por qué las enfermedades prevalecían más en invierno que en verano, estableciendo una relación entre el calor del sol, la nubosidad, el aire frío y la mala ventilación.

En general, el calor del sol era visto con temor, ya que facilitaba la fermentación y la descomposición de las materias orgánicas que se acumulaban, "según el principio generalmente reconocido, de que el aire caliente ocasiona más exhalaciones en los cuerpos que el aire fresco..."24. Sin embargo, Blest llamaba la atención de que en Chile no era el verano donde más enfermedades ocurrían sino el invierno. Ello lo explicaba por situaciones particulares que existían en el país, donde se establecía una relación específica entre las condiciones atmosféricas y la nubosidad. Blest le dio mucha importancia a la variación de las condiciones atmosféricas, llegando a plantear que en verano se daba un benéfico estado de la atmósfera que favorecía la buena ventilación y la circulación del aire limpio.

Al gozar Santiago de cielos claros durante el verano, los miasmas no quedaban atrapados en la atmósfera, mientras que, en el invierno, "esos vapores se encuentran con las nubes que nos rodean, y consiguientemente son precipitados a la tierra y echados por la brisa nocturna al interior de las habitaciones" 25 . Si a ello se sumaba la mala ventilación que tenían las habitaciones, se encontraba la causa de por qué el invierno los pobres se enfermaban más.

Tanto la teoría miasmática como los negativos efectos de la insalubridad de Santiago, fueron elementos importantes en las explicaciones que Blest construyó respecto al origen de las enfermedades, poniendo en evidencia la relevancia de mejorar la higiene urbana, así como la relación entre pobreza y el mayor padecimiento de enfermedades. Igualmente, expuso la importancia de factores como el clima y la temperatura, los cuales actuaron como determinantes geográficos de la enfermedad.

\section{Conclusión}

En el marco de las doctrinas fisiologistas y tomando elementos planteados por Brown y Broussier, Guillermo Blest expuso las causas de las enfermedades que afectaban a Chile. Sus explicaciones consideraron tanto el principio de la excitabilidad como el de la irritabilidad en el origen de la enfermedad, en tanto generaban algún tipo de desequilibrio en el funcionamiento del cuerpo humano. Estos principios coexistieron con la teoría miasmática y, en conjunto, permitieron a Blest explicar el fenómeno de la enfermedad. 
Para Blest había un conjunto de determinantes geográficos, como el clima, que eran constitutivos de cada lugar y que entregaban elementos para comprender el porqué de la enfermedad. Sin embargo, dichos determinantes se combinaban con condiciones particulares de cada país y población, que también resultaron centrales en la comprensión de dicho fenómeno. Es decir, la consideración que hizo respecto a las causas de la enfermedad incluyó tanto determinantes externos como factores de carácter cultural o social sujetos al cambio, ello le permitió considerar que el mejoramiento de la policía urbana, de la higiene individual y colectiva, de la alimentación, junto a las indicaciones que debían entregar los médicos, hacía posible enfrentar y evitar determinadas enfermedades, más allá de los determinantes geográficos que podían existir. De este modo, un buen médico, señalaba Blest, era quien sabía ponderar adecuadamente el conocimiento de las teorías generales de la medicina con el conocimiento específico del lugar donde el medico ejercía su profesión. Un buen ejemplo de ello, fue el carácter social que podía llegar a tener la enfermedad, en tanto puso en evidencia la relación que existía entre enfermedad y pobreza como factores relevantes en su producción y propagación.

Finalmente, el análisis que hemos realizado nos permite comprender los sustentos teóricos que estuvieron tras los planteamientos de Guillermo Blest. En ellos podemos ver la presencia tanto de la teoría fisiologista como de la teoría miasmática, pero será la mixtura de ambas lo que le permitió configurar un cuadro explicativo sobre el origen de la enfermedad, capaz de integrar tanto los elementos de las teorías generales como las particularidades que observaba en el territorio chileno.

\section{Referencias bibliográficas}

1.- Armus, Diego. La enfermedad en la historiografía de América Latina moderna, p. 42. Asclepio-Vol. LIV-2-2002.

2.- Serrano, Sol. Universidad y Nación. Santiago: Universitaria; 2016, p. 179.

3.- Barros Arana, Diego. Historia General de Chile, vol. 15.
Santiago: Universitaria; p. 226.

4.- Nota de Diego Portales al presidente del Protomedicato Guillermo Blest, Fondo Ministerio del Interior, Archivo Nacional, vol. 165, s/f, 25 de enero de 1836.

5.- Blest, Guillermo. Ensayo sobre las causas más comunes y activas de las enfermedades que se padecen en Santiago de Chile con indicaciones de los mejores medios para evitar su destructora influencia. Santiago: Imprenta de R. Rengifo; 1828 , p. 9.

6.- Arquiola, Elvira y Montiel, Luis. La Corona de la Ciencias Naturales. La medicina de tránsito del siglo XVIII al XIX. Madrid: CSIC; 1993, p. 283.

7.- Arquiola y Montiel, p. 313 a 315. Para profundizar en los planteamientos de John Brown, véase Elementa Medicinae. Sumtibus I. G. Hanisch, 1794.

8.- Arquiola y Montiel, p. 297 y 298.

9.- Blest, p. 23.

10.- Blest, p. 24.

11.- Blest, p. 23.

12.- Blest, p. 32 y 33.

13.- Blest, p. 34.

14.- Blest, p. 52 y 53.

15.- Blest, p. 57.

16.- Blest, p. 10.

17.- Blest, p. 10.

18.- Blest, p. 14 y 15.

19.- Bynum, W.F. Science and the Practice of Medicine in the Nineteenth Century. Cambridge: Cambridge University Press; 1994, p. 45.

20.- Los miasmas eran entendidos como exhalaciones pútridas y vapores liberados por la materia orgánica vegetal o animales en descomposición. El origen de las epidemias se debía justamente a la presencia de algún miasma que emanaba de la materia orgánica en descomposición. De este modo, la acumulación de éstos explicaba el origen de las enfermedades. Véase Márquez Valderrama, Jorge. Ciudad, miasmas y microbios: la irrupción de la ciencia pasteriana en Antioquia. Antoquia: Universidad de Antioquia; 2005.

21.- Blest, p. 13.

22.- Oficio del presidente del Protomedicato al Sr. ministro del Interior, El Araucano, Valparaíso, 4 de enero de 1832.

23.- Informe enviado por Guillermo Blest al Gobernador de Valparaíso, 5 de enero de 1832, Fondo Ministerio del Interior, Archivo Nacional, f. 81, vol. 106.

24.- Blest, p. 17.

25.- Blest, p. 19. 